\title{
Identification of factors influencing teat dip efficacy trial results by meta-analysis
}

\author{
B. D. Enger, ${ }^{* 1}$ R. R. White, ${ }^{*}$ S. C. Nickerson, $\dagger$ and L. K. Fox $\ddagger$ \\ *Department of Dairy Science, Virginia Polytechnic Institute and State University, Blacksburg 24061 \\ †Department of Animal and Dairy Science, University of Georgia, Athens 30602 \\ ‡Department of Veterinary Clinical Sciences, Washington State University, Pullman 99164
}

\begin{abstract}
Two meta-analyses were conducted using data from peer-reviewed natural exposure (NE) and experimental challenge (EC) teat dip efficacy trials to identify factors influencing the new intramammary infection (IMI) rate. A NE data set containing 16 studies and an EC data set containing 21 studies were created. New IMI rate was calculated based on the percentage of new quarter infections per month (PNQI/mo) for each observation, in both data sets, and used as the dependent variable for model derivation. A linear, mixedeffects model with a random study effect, weighted by number of quarters eligible for infection, was derived for each data set. The final NE model included the effects of experimental design (split herd or split udder), mastitis pathogen group (Staphylococcus aureus, Streptococcus agalactiae, environmental streptococci, gram-negative species, Corynebacterium spp., or coagulase-negative staphylococci), postmilking treatment (iodine, chlorhexidine, linear dodecyl benzene sulfonic acid, chlorine compounds, phenol compounds, or undipped negative controls), and the interaction between mastitis pathogen group and postmilking treatment. Overall, Corynebacterium spp. had the highest new IMI rate $(0.0139 \pm 0.0018 \mathrm{PNQI} / \mathrm{mo})$, and environmental streptococci and gram-negative species had the lowest (0.0023 $\pm 0.0022 \mathrm{PNQI} / \mathrm{mo})$. Additionally, trials utilizing a split herd experimental design had a 2-fold higher new IMI rate than trials using a split udder design. The final EC model included the effects of mastitis pathogen (Staph. aureus and Strep. agalactiae), postmilking treatment (iodine, chlorine compounds, "other" active ingredients, or undipped negative controls), geographic region of study (Eastern, Southern, and Pacific Northwest), and the 2-way interactions of region and pathogen group and postmilking treatment
\end{abstract}

Received April 25, 2016.

Accepted August 15, 2016.

${ }^{1}$ Corresponding author: benger@vt.edu and pathogen group. Overall, Staph. aureus and Strep. agalactiae had similar new IMI rates. Quarters dipped postmilking in either iodine (0.0127 $\pm 0.0099 \mathrm{PNQI} /$ $\mathrm{mo})$, chlorine compounds $(0.0258 \pm 0.0095 \mathrm{PNQI} / \mathrm{mo})$, or "other" active ingredient teat dips $(0.0263 \pm 0.0106$ PNQI/mo) had lower new IMI rates than undipped quarters $(0.0859 \pm 0.0087 \mathrm{PNQI} / \mathrm{mo})$. These results indicate that experimental design influences the new IMI rate of teat dip efficacy trials and that using an effective postmilking teat dip has a greater effect on controlling the new Staph. aureus and Strep. agalactiae IMI rate than the teat dip's active ingredient.

Key words: natural exposure, experimental challenge, split udder, mastitis

\section{INTRODUCTION}

Teat disinfectants (teat dips) are important tools used to prevent mastitis in the modern dairy industry. Disinfection of teats before milking reduces the incidence of IMI caused by environmental mastitis pathogens (Pankey and Drechsler, 1993), and disinfection of teats after milking reduces the incidence of IMI caused by opportunistic and contagious mastitis pathogens (Pankey et al., 1984b; Quirk et al., 2012). The efficacy of a teat dip is determined not only by the active ingredient and its concentration, but by many additional factors. Consequently, testing all teat dips in a herd setting is important to confirm efficacy before commercial distribution. To date, many trials have been conducted to determine and confirm the efficacies of different teat dip formulations; however, a broad, quantitative synthesis of this body of literature has not yet been undertaken.

Quantitatively characterizing the factors that influence teat dip efficacy will allow for (1) more robust evaluation of teat dip-pathogen interactions; (2) evaluation of the importance of management variables such as utilizing pre- and postmilking teat dips and the corresponding active ingredient concentrations; and (3) quantitative understanding of differences among experimental approaches. Meta-analysis is a useful tool 
for summarizing previous literature that investigates the efficacy of different teat dips (St-Pierre, 2001; Sauvant et al., 2008). The objective of the present study was to use a meta-analysis approach to identify factors that significantly influenced the reported new IMI rates presented in peer-reviewed teat dip efficacy trials.

\section{MATERIALS AND METHODS}

\section{Literature Search}

Data from previously published, peer-reviewed studies that described efficacies of teat dips in reducing incidence of new IMI were obtained for this analysis. Inclusion and exclusion criteria established were a function of teat dip study design (natural exposure, NE, or experimental challenge, EC) and will be explained in subsequent sections.

In 1994, the National Mastitis Council (NMC) Research Committee began compiling a list of teat disinfectant studies published since 1980 that used either an $\mathrm{NE}$ or EC design to determine teat dip efficacy. In its last revision (NMC, 2014), this publication summarized 51 studies that were based on the following criteria: (1) only peer-reviewed publications were included; (2) only the information published within the study was summarized; (3) the study followed the NE or EC testing protocols; (4) studies reporting only nonsignificant results were not included, except NE studies using a positive control; and (5) publications must have included either the trade name or the manufacturer's information for the tested teat disinfectant. For the present study, the NE and EC studies cited within the 2014 NMC report were further refined based on the selection criteria described in the following sections and used to construct a data set of similar study designs.

\section{Inclusion and Exclusion Criteria and Variables of Interest}

The common inclusion and exclusion criteria applied to both NE and EC studies are described in this section, and the criteria specific to each study design (NE or EC) are outlined in the following sections. The NE and EC studies meeting the respective inclusion and exclusion criteria are presented in Tables 1 and 2. For inclusion in the respective data set, all studies must have only used products that were intended for commercial use. All studies included had either a split herd design in which all quarters of a single cow received the same treatment or a split udder design in which the right and left udder halves received different treatments. When a variable of interest was absent from the published manuscript, the corresponding author or the manufacturer was contacted to obtain this information.

\section{Natural Exposure Studies}

A total of 24 manuscripts utilizing an NE study design were identified from the NMC's teat disinfectant summary. Only studies using a teat disinfectant product of a single disinfectant class were included in the database, allowing for comparisons between different germicide active ingredient classes. Based on the pre-

Table 1. List of peer-reviewed reports contained in the natural exposure data set and corresponding study characteristics

\begin{tabular}{|c|c|c|c|c|}
\hline Study & Study region ${ }^{1}$ & Teat dips used & Control type $^{2}$ & Study design \\
\hline Drechsler et al., 1990 & Eastern & Postmilking & Positive postmilking & Split udder and herd \\
\hline Oliver et al., 1989 & Southern & Postmilking & Negative postmilking & Split udder \\
\hline Oliver et al., 1990 & Southern & Postmilking & Negative postmilking & Split udder \\
\hline Oliver et al., 1991 & Southern & Postmilking & Negative postmilking & Split udder and herd \\
\hline Oliver et al., 1994 & Southern & Pre- and postmilking & Negative premilking & Split udder \\
\hline Oliver et al., 1999 & Southern & Postmilking & Negative postmilking & Split udder \\
\hline Oliver et al., 2001 & Southern & Pre- and postmilking & Negative premilking & Split udder \\
\hline Pankey et al., 1984a & Southern & Postmilking & Negative postmilking & Split herd \\
\hline Pankey et al., $1985 \mathrm{~b}$ & Southern & Postmilking & Negative postmilking & Split herd \\
\hline Pankey et al., 1987 & Eastern & Pre- and postmilking & Negative premilking & Split herd \\
\hline Peters et al., 2000 & Eastern & Pre- and postmilking & Positive premilking & Split herd \\
\hline
\end{tabular}

${ }^{1}$ Study locations were classified as either the Southern (Louisiana and Tennessee), Eastern (Vermont and Maryland), or the Pacific Northwest (Idaho) region of the United States.

${ }^{2}$ Negative control quarters were not treated with the dip specified and positive controls quarters were treated with an already demonstrated pre- or postmilking teat dip. 
ceding criteria, 16 reports containing 256 observations were included in the final constructed database.

All variables included in the final $\mathrm{NE}$ model are summarized in Table 3. An array of different mastitis pathogens were identified as causative agents within the identified reports. For this reason, the causative mastitis pathogens were classified as being either (1) Staphylococcus aureus, (2) Streptococcus agalactiae, (3) environmental streptococci, (4) gram-negative species, (5) Corynebacterium spp., or (6) CNS. Assigning the reported causative agents to 1 of these 6 pathogen groups allowed for more appropriate comparisons to be made because speciation methods likely differed among laboratories and have changed over time. Study locations were also grouped into regions to help control for differences in environmental factors and pathogen prevalence; these were the Southern, Eastern, and Pacific Northwest regions of the United States. As a result, 12 studies were labeled as being from the Southern region, 3 studies as Eastern, and 1 study as Pacific Northwest (Table 1). The percentage of observations in the NE data set identified by region are presented in Table 3. The use of pre- and postmilking teat dips in the reported studies, either alone or in combination, was recorded for each observation, and each teat dip was characterized based on its germicidal active ingredient class into disinfectant classes [iodine, chlorhexidine, linear dodecyl benzene sulfonic acid (LDBSA), chlorine compounds other than chlorhexidine, or phenol

Table 2. List of peer-reviewed reports and corresponding study regions contained in the experimental challenge data set

\begin{tabular}{ll}
\hline Experimental challenge & Study region $^{1}$ \\
\hline Boddie and Nickerson, 1986 & Southern \\
Boddie and Nickerson, 1989 & Southern \\
Boddie and Nickerson, 1990 & Southern \\
Boddie and Nickerson, 1992 & Southern \\
Boddie and Nickerson, 1996 & Southern \\
Boddie and Nickerson, 1997 & Southern \\
Boddie and Nickerson, 2002 & Southern \\
Boddie et al., 1990 & Southern \\
Boddie et al., 1993 & Southern \\
Boddie et al., 1994 & Southern \\
Boddie et al., 1997 & Southern \\
Boddie et al., 1998 & Southern \\
Boddie et al., 2000 & Southern \\
Boddie et al., 2004 & Southern \\
Drechsler et al., 1990 & Eastern \\
Foret et al., 2003 & Southern \\
Fox et al., 2006 & Pacific Northwest \\
Oura et al., 2002 & Pacific Northwest \\
Pankey et al., 1983 & Southern \\
Pankey et al., 1984c & Southern \\
Pankey et al., 1985a & Southern \\
\hline
\end{tabular}

${ }^{1}$ Study locations were classified as either the Southern (Louisiana), Eastern (Vermont), or the Pacific Northwest (Washington State) region of the United States. compounds; Table 3]. Quarters not treated with a teat disinfectant served as undipped negative controls for the respective premilking, postmilking, or both types of treatment and were included in the data set. In addition to these extracted and categorized data, other variables were (1) year of study, (2) experimental design (split herd or split udder), (3) premilking teat dip active ingredient concentration, (4) postmilking teat dip active ingredient concentration, (5) presence of a skin conditioning agent in the postmilking teat dip, and (6) whether the postmilking teat dip was identified as a barrier-type product in the final publication or product description. The response variable used for analysis was defined as the percentage of new quarter infections per month (PNQI/mo) and calculated using the equation

$$
\mathrm{PNQI} / \mathrm{mo}=\frac{N_{i} / E_{j}}{D_{k} / \mathrm{mo}}
$$

where $N_{i}=$ number of quarters that became infected during trial; $E_{j}=$ number of quarters eligible for infection at start of trial; $D_{k}=$ trial duration expressed in days; and mo $=28 \mathrm{~d}$. In instances in which the number of quarters eligible for new infection was not explicitly stated, the number was calculated using the total number of quarters in the experiment minus the number of existing infections at the beginning of the trial. The PNQI/mo or new IMI rate was calculated for both dipped and undipped negative control quarters.

\section{Experimental Challenge Studies}

Twenty-eight articles identified from the NMC's teat disinfectant summary used an EC design. Only studies that challenged quarters once daily, 5 times a week, immediately after milking, were included in the data set. Only studies examining teat dips containing germicides of a single disinfectant class were included to allow for direct comparison of active ingredient product classes. The remaining studies included in the data set all used a postmilking teat dip that was compared with a negative control and had a split udder design in which 2 teats of each cow were treated with the experimental germicide and the remaining 2 served as undipped negative controls. Based on these specifics and the previously described general criteria, 7 reports were excluded from analysis and the remaining 21 were used, yielding a total of 148 observations.

All variables included in the final EC model are summarized in Table 3. Within the included reports, only Staph. aureus (Newbold 305; ATCC 29740) and Strep. agalactiae (McDonald 44; ATCC 27956) were 
Table 3. Descriptive statistics of the constructed natural exposure and experimental challenge data sets

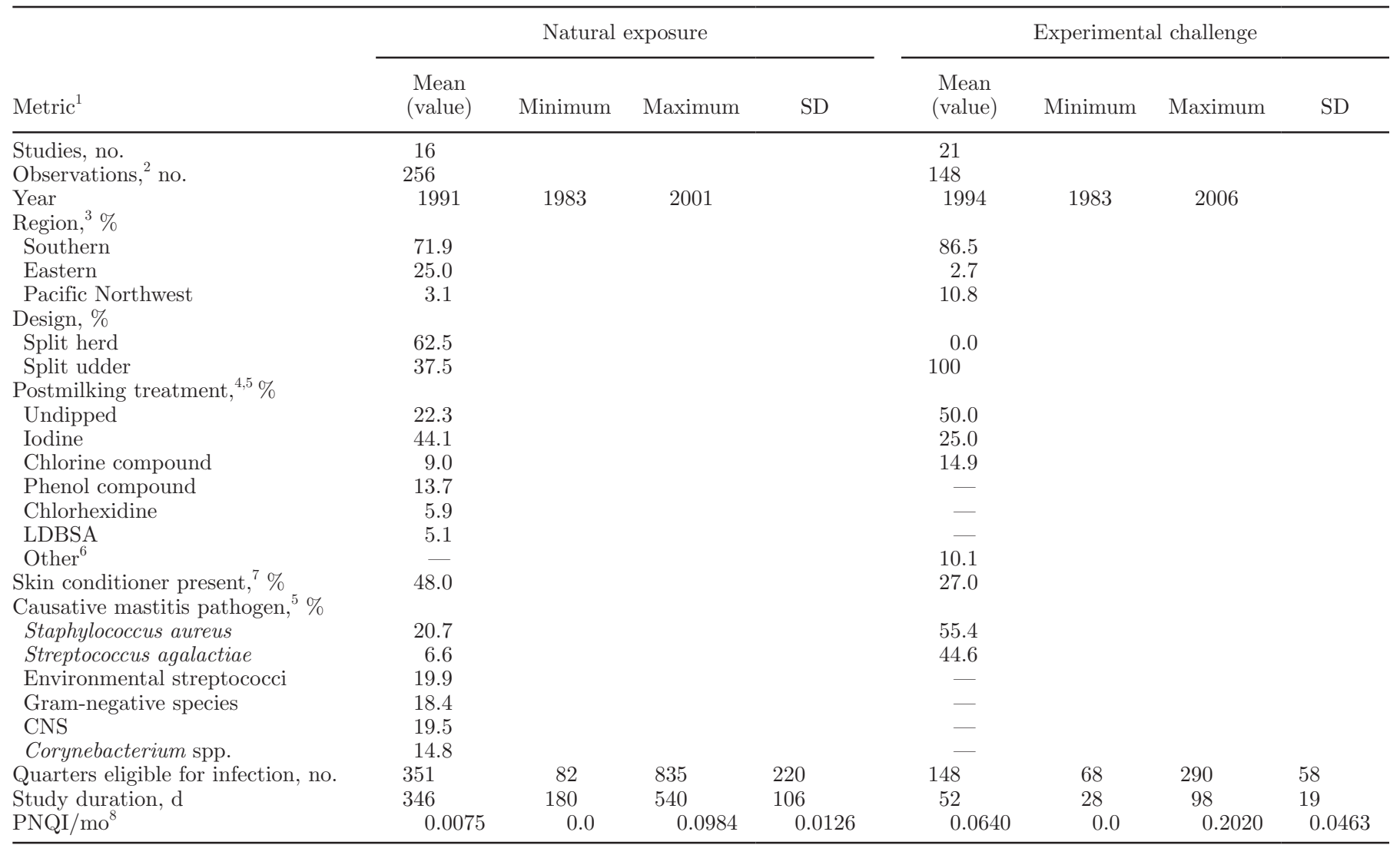

${ }^{1}$ Calculated percentages represent the percentage of observations positive for the respective characteristic in the corresponding data set.

${ }^{2}$ The number of total observations. An observation was defined as any unique pathogen, treatment combination within a study for which an infection rate was calculated.

${ }^{3}$ Study locations were classified as either the Southern (Louisiana and Tennessee), Eastern (Vermont and Maryland), or the Pacific Northwest (Washington State and Idaho) region of the United States.

${ }^{4}$ Cow's teats were either not treated with a postmilking teat dip (undipped) or dipped in teat dip containing iodine, chlorhexidine, linear dodecyl benzene sulfonic acid (LDBSA), a chlorine compound, a phenol compound, or other.

${ }^{5}$ Postmilking treatment and causative mastitis pathogen percentages did not add up to $100 \%$ because of rounding errors.

${ }^{6}$ For the experimental challenge data set, teat disinfectants not containing either iodine or a chlorine compound as the active ingredient were collectively classified as "other."

${ }^{7}$ Percentage of observations containing a skin conditioning agent in the postmilking teat dip.

${ }^{8}$ Percentage of new quarter infections per month $(\mathrm{PNQI} / \mathrm{mo})=$ percentage of quarters eligible for infection that became infected during the trial divided by trial duration expressed as months.

used in challenge suspensions. Study locations were grouped into the regions of the United States described previously. This approach resulted in 18 studies being labeled as coming from the Southern region, 1 study from the Eastern, and 2 studies from the Pacific Northwest (Table 2). The percentage of observations in the data set classified by each region are presented in Table 3. Few studies used a germicidal active ingredient other than iodine or chlorine compounds other than chlorhexidine, which prevented making relevant comparisons among the remaining germicide active ingredient classes. These disinfectants were grouped and described as the "other" classes. Consequently, the final data set included the germicidal classes iodine, chlorine compounds other than chlorhexidine, and "other" as postmilking treatments. Identical to the NE data set, the undipped negative control teats were included as a postmilking treatment. Additional variables were (1) year of study, (2) postmilking teat disinfectant active ingredient concentration, and (3) the presence of a skin conditioning agent in the postmilking teat disinfectant. The response variable used for analysis in the EC data set was PNQI/mo.

\section{Selection Bias and Heterogeneity Evaluations}

Study selection bias and study heterogeneity are 2 primary concerns within meta-data. Publication bias 
was evaluated based on visual assessment of funnel plot heterogeneity. Funnel plots are included in Supplemental Figure S1 (http://dx.doi.org/10.3168/jds.201611359). In both the NE and EC data sets, a high degree of symmetry was demonstrated by the funnel plots, suggesting minimal publication bias. Heterogeneity across studies is almost inevitable in meta-analyses. This heterogeneity typically takes 1 of 2 forms: (1) differences in the mean value observed across studies but similar response surfaces, or (2) differences in the response surface observed across studies. To evaluate the nature of the heterogeneity in this study, we evaluated the slope of new IMI rate on the control treatment compared with the analogous teat dip treatment by teat dip class and pathogen type. These relationships are depicted in Supplemental Figures S2 through S4 (http://dx.doi. org/10.3168/jds.2016-11359) and, in general, show extremely parallel slopes across studies. In this case, the heterogeneity in the data appears to be best explained by a difference in the intercept (basal infection rate) associated with each study. The statistical analysis used was designed to account for this heterogeneity.

\section{Statistical Analysis}

The MIXED procedure in SAS 9.4 (SAS Institute Inc. Cary, NC) was used to derive models. Significances of parameter estimates were calculated assuming the Kenward-Roger denominator degrees of freedom correction (Kenward and Roger, 1997). All models were derived using stepwise, linear, mixed-effect regression in which PNQI/mo was the dependent variable, study identifier was used as a random effect, and observations were weighted by the number of eligible quarters reported in a study. Following previous meta-analyses, the weight parameter (quarters eligible for infection) was truncated at twice the mean number of eligible quarters if more than twice the mean number of quarters was used. This adjustment was performed to prohibit overweighting disproportionately large studies. The number of quarters was normalized so that the mean was equal to 1 . The normalized, truncated quarter counts were used as weights for each treatment.

Model derivation followed a multiphase, stepwise elimination procedure. An initial stepwise phase was performed in which variables were sequentially eliminated from the model for nonsignificance $(P>0.1)$. Corrected Akaike information criteria (AICc; Hurvich and Tsai, 1993) were used at each step to ensure that the removal of the variable improved the probability of the model given the data and to determine if variables with tendencies toward significance $(0.1>P>0.05)$ should be included or removed. Where AICc shifted minimally, variance inflation factors were also calculated to determine the severity of the multicollinearity between variables. Variables were removed if the variance inflation factor was greater than 100 . In the initial stepwise phase of the model derivation procedure, only class effects for study design, species, and postmilking treatment were included in the NE model; the class effects included in the initial EC model were region and postmilking treatment.

In the second phase of the model derivation procedure, interactions between the remaining significant variables were tested to identify whether any interaction terms were significant. Additionally, the residuals of the model were tested against explanatory variables that had been removed during the stepwise procedure to ensure that no variables had been removed because of model instability rather than nonsignificance.

Tukey-Kramer's multiple comparison procedure was used to contrast the least squares means yielded from the final respective models, and a PROC MIXED macro (Saxton, 1998) was used to sort the generated output.

\section{RESULTS AND DISCUSSION}

\section{Natural Exposure Model}

In addition to the random and weighting variables discussed previously, the fixed independent variables included in the final NE model were study design (n $=2)$, mastitis pathogen group $(\mathrm{n}=6)$, postmilking treatment $(n=6)$, and the interaction between pathogen group and postmilking treatment. The fit statistics of the final NE model are presented in Table 4, and the parameter estimates and their significance values are outlined in Supplemental Table S1 (http://dx.doi. org/10.3168/jds.2016-11359). The final NE model had a very low residual error $(0.50 \%$ for $\mathrm{NE})$, suggesting that the derived model fit the data with high precision and accuracy. The error assigned to individual studies

Table 4. Fit statistics of the final natural exposure (NE) and experimental challenge (EC) models

\begin{tabular}{lcc}
\hline Fit statistic $^{1}$ & NE model & EC model \\
\hline$\hat{\sigma}_{s}$ & $1.9 \times 10^{-5}$ & $1.96 \times 10^{-4}$ \\
$\hat{\sigma}_{e}$ & $3.7 \times 10^{-5}$ & $5.67 \times 10^{-4}$ \\
$\hat{\sigma}_{e}, \%$ of mean & 0.50 & 0.88 \\
$\hat{\sigma}_{s}+\hat{\sigma}_{e}, \%$ of mean & 0.75 & 1.2 \\
$\hat{\sigma}_{e} / \hat{\sigma}_{s}$ & 1.95 & 2.89 \\
$\mathrm{AICc}^{2}$ & $-1,487$ & -568 \\
\hline
\end{tabular}

${ }^{1}$ Where $\hat{\sigma}_{s}=$ error variance associated with study; and $\hat{\sigma}_{e}=$ residual error variance.

${ }^{2}$ Corrected Akaike information criterion. 
was only $0.25 \%$ of the mean observed new IMI rate. The relatively small contribution of error from study suggests that minimal between-study variability was not accounted for by the terms included in the model. In models with high heterogeneity among studies, the ratio of residual error to study error often exceeds 5 . The relatively low ratio identified in this model indicates that study heterogeneity was not an excessive source of error in the model.

Significant differences existed among causative mastitis pathogen groups in the dependent variable, PNQI/ mo $(P<0.0001)$; the corresponding least squares means are reported and contrasted in Table 5. Corynebacterium spp. (0.0139 PNQI/mo) had the highest new IMI rate across all study designs and postmilking treatments, while the environmental streptococci $(0.0023$ $\mathrm{PNQI} / \mathrm{mo}$ ) and gram-negative species (0.0023 PNQI/ mo) had the lowest. New IMI rate for the CNS (0.0094 PNQI/mo) tended to be higher than the infection rate of Staph. aureus (0.0046 PNQI/mo; $P=0.0697$ ). The relationship of these IMI rates with the different mastitis pathogen groups was expected. Many reports have noted that Corynebacterium spp. and CNS have a greater IMI prevalence on dairy farms than the environmental mastitis pathogens (environmental streptococci and gram-negative species), which classically have the lowest IMI prevalence (Wilson et al., 1997; Pitkälä et al., 2004; Devries et al., 2011). A significant interaction existed between the causative mastitis pathogen groups and the postmilking treatments in their effect on the dependent variable, $\mathrm{PNQI} / \mathrm{mo}(P=0.0009)$. The presence of this interaction, which is illustrated in Figure 1, was also expected. In addition to the known differences in mastitis pathogen IMI prevalences on dairies, mastitis pathogens have also been demonstrated to vary in sensitivity to different teat dips (Schmidt et al., 1984; Enger et al., 2015). When the new IMI rates of postmilking treatments were contrasted within mastitis pathogen groups, differences were only observed within Corynebacterium spp. Quarters dipped in an LDBSA dip had a greater new IMI rate for Corynebacterium spp. than those dipped in iodine, chlorhexidine, a phenol compound, or a chlorine compound $(P<0.05)$. Undipped quarters did not differ in new IMI rate for Corynebacterium spp. from quarters dipped in LDBSA, iodine, chlorhexidine, phenol compounds, or chlorine compound dips $(P>0.05)$. The effects of the LDBSA teat dip on the IMI rate for the Corynebacterium spp. aligns with a previous study, not included in the data set, that reported a greater IMI rate for several pathogens including Corynebacterium spp. for quarters dipped with LDBSA teat dips than those dipped with iodine teat dips (Watts et al., 1991). Taken together, these results support previous findings that LDBSA teat dips are not effective in controlling the incidence of Corynebacterium spp. IMI (Hogan et al., 1999).

When the new IMI rates of mastitis pathogen groups were contrasted within postmilking treatments, significant differences were only detected in untreated negative control quarters and quarters dipped in LDBSA. These differences, discussed below, are illustrated in panels A and B of Figure 2. Undipped quarters had a greater new IMI rate for Corynebacterium spp. than gram-negative species and environmental streptococci (Figure $2 \mathrm{~A} ; P<0.05$ ); this infection rate was not different from that of Strep. agalactiae, Staph. aureus, or CNS $(P>0.05)$. Quarters dipped in a LDBSA teat dip had a significantly greater new IMI rate with Corynebacterium spp. compared with Staph. aureus, environmental streptococci, and gram-negative species (Figure 2B; $P<0.05$ ) but not CNS or Strep. agalactiae $(P<0.05)$. The negative new IMI rates illustrated in Figure $2 \mathrm{~B}$ are the same as those presented in Figure 1. Negative least squares means estimates indicate that on average, the model predicted slight negative values for those parameter combinations. This mathematical artifact is likely due to the model attempting to use combinations of categorical variables to predict values very close to 0 . In these conditions, the best-fit line will often underestimate some values very close to 0 (produce negative estimates), while others will overestimate values that are very close to 0 . Negative least squares means estimates should be interpreted as 0 because this value is the lowest that is biologically feasible. Although negative new IMI rates were calculated in 2 instances and would be interpreted as a new IMI rate of 0 , the relationship of the calculated negative and positive values is still valid and arguably more important than the least squares means estimates themselves.

Studies utilizing a split herd design to test teat dip efficacy had a significantly higher infection rate $(0.0089$

Table 5. Mastitis pathogen group percentage of new quarter infections per month (PNQI/mo) ${ }^{1}$ least squares means across all postmilking treatments and study designs for the natural exposure data set

\begin{tabular}{lr}
\hline Mastitis pathogen group & PNQI/mo $( \pm \mathrm{SEM})$ \\
\hline Staphylococcus aureus & $0.0046^{\mathrm{BC}} \pm 0.0017$ \\
Streptococcus agalactiae & $0.0054^{\mathrm{ABC}} \pm 0.0043$ \\
Environmental streptococci & $0.0023^{\mathrm{C}} \pm 0.0020$ \\
Gram-negative species & $0.0023^{\mathrm{C}} \pm 0.0022$ \\
CNS & $0.0094^{\mathrm{AB}} \pm 0.0017$ \\
Corynebacterium spp. & $0.0139^{\mathrm{A}} \pm 0.0018$ \\
\hline
\end{tabular}

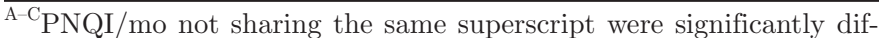
ferent $(P<0.05)$.

${ }^{1}$ Percentage of quarters eligible for infection that became infected during the trial divided by trial duration expressed as months. 


\section{Postmilking Treatment Chlorhexidine Chlorine compound $\boldsymbol{B} \boldsymbol{B}$ lodine LBSA XXX Phenol compound Undipped negative control}

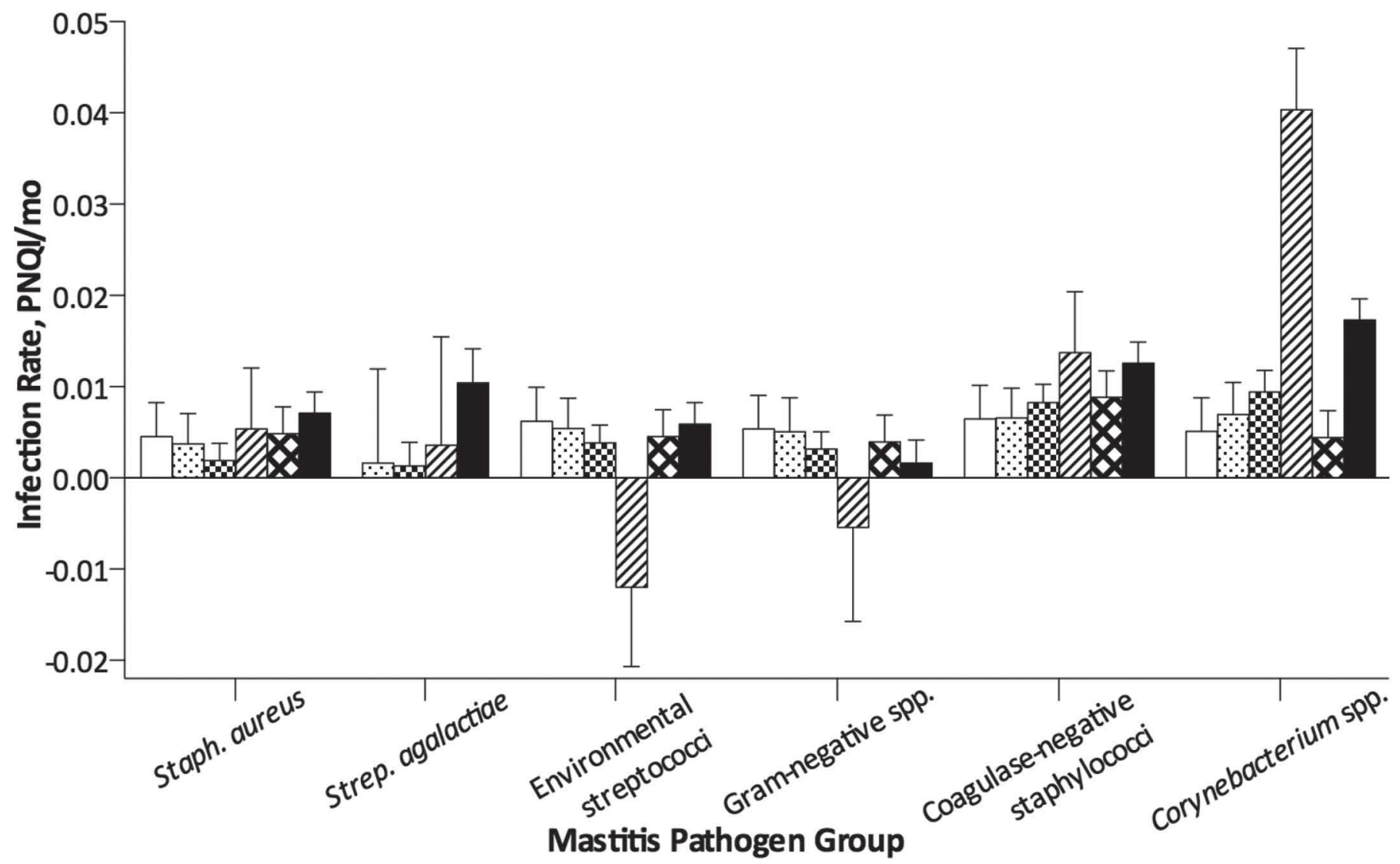

Figure 1. The percentage of new quarter infections per month $(\mathrm{PNQI} / \mathrm{mo})=$ percentage of quarters eligible for infection that became infected during the trial divided by trial duration expressed as months. For the natural exposure data set, cows' teats were either undipped negative controls or dipped in a teat dip containing iodine, chlorhexidine, linear dodecyl benzene sulfonic acid (LDBSA), a chlorine compound, or a phenol compound. Values presented are the calculated PNQI/mo least squares means \pm SEM. Staph. $=$ Staphylococcus; Strep. $=$ Streptococcus .

$\pm 0.0017 \mathrm{PNQI} / \mathrm{mo})$ compared with studies utilizing a split udder design $(0.0046 \pm 0.0017 \mathrm{PNQI} / \mathrm{mo} ; P$ $=0.0343)$. This result is explained, at least in part, by the report of Dodd and colleagues (1977) in which researchers studied new IMI rates at both the cow and quarter levels of 14 herds over 12 mo. Sixty-five percent of the new IMI was reported to occur in cows with at least 1 already infected quarter, indicating that the majority of new IMI cases are the result of infection spreading from one quarter to another in the same animal, most likely during milking. This finding supports the model's result because the spread of infection from quarter to quarter of the same cow is expected to be reduced in spilt udder studies because 2 quarters are protected from infection via teat dipping, and these same 2 dipped quarters would be expected to have a protective effect on the undipped quarters because they are less likely to be infected themselves. This protec- tive effect would apply to all animals in a split udder study; however, the animals assigned to the undipped negative control treatment in a split herd study would not experience this protective effect. In addition, it is important to recognize that split udder studies reduce variation by design. Thus, one recommendation could be that future teat dip efficacy studies use a split udder design to reduce experimental variation in addition to minimizing the effect of teat dip efficacy trials on herd udder health unless studies use a positive control.

Other explanatory variables such as the concentration of a dip's active ingredient, the presence of a skin conditioner in a postmilking teat dip, geographical region of study, and the use of a premilking teat dip did not influence new IMI rate $(P>0.05)$. Scant evidence supports a relationship between the concentration of a dip's active ingredient and dip efficacy, supporting the model's results. One study included in the data 


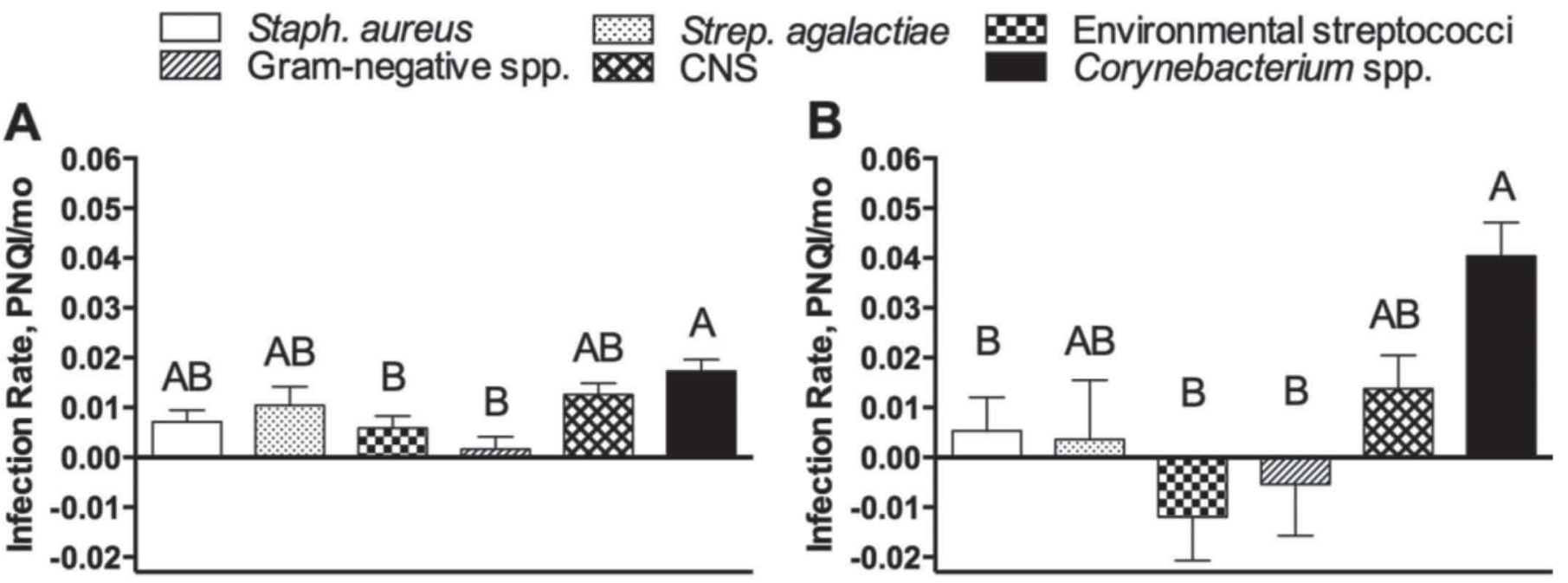

Mastitis Pathogen Group

Figure 2. The percentage of new quarter infections per month $(\mathrm{PNQI} / \mathrm{mo})=$ percentage of quarters eligible for infection that became infected during the trial divided by trial duration expressed as months. Mean mastitis pathogen group PNQI/mo \pm SEM for the natural exposure data set are depicted for undipped negative control quarters (A) and quarters dipped with a linear dodecyl benzene sulfonic acid teat dip (B). Means not sharing the same letter above bars within panels were significantly different from one another $(P<0.05)$. No significant differences in the PNQI/mo were observed between mastitis pathogen groups within the remaining postmilking treatment groups $(P>0.05)$. Staph. $=$ Staphylococcus; Strep. $=$ Streptococcus.

set did not identify differences in the number of new IMI between 3 different teat dips containing 1.0, 0.25, and $0.1 \%$ iodine (Bray et al., 1983). A separate study, not included in the data set, compared an experimental teat dip to a proven positive control teat dip, each containing $0.25 \%$ iodine, and reported a $55 \%$ reduction in the number of new IMI for quarters dipped in the experimental teat dip compared with quarters dipped with the positive control teat dip (Foret et al., 2005). The increased efficacy was attributed to differences in product formulation, which increased the available free iodine. Taken together, the concentration of a teat dip's active ingredient may not be a good predictor of efficacy as other factors, such as available free iodine, influence efficacy.

The final model was unable to identify a relationship between use of a premilking teat dip and new IMI rate, disagreeing with a proven mastitis control practice (Pankey and Drechsler, 1993). This lack of a significant relationship between premilking teat dip use and new IMI rate reflects a problem with the data, rather than a true biological response. Only 7 of the 16 studies in the data set used a premilking teat dip (Table 1). Premilking teat dips have demonstrated efficacy against environmental streptococci and gram-negative species (Pankey et al., 1987), the 2 pathogen groups with the lowest new IMI rate in the data set. Furthermore, Pankey and Drechsler (1993) indicate that housing, par- ity, season, and DIM are also important variables that can influence the risk of environmental IMI in dairy cows. Thus, considering the limited number of studies, the low new environmental pathogen IMI rates, and the other variables that could not be included in the model, it is not surprising that the model was unable to describe the effects that premilking teat dips would be expected to have on environmental pathogen IMI rates. Had a larger data set of premilking teat dip studies been included, a higher IMI rate been available, and a more comprehensive description of these other variables been presented, it is likely that the model would have been able to more precisely characterize the relationship between premilking teat dip use and new environmental pathogen IMI rate.

\section{Experimental Challenge Model}

Accompanying the weighting and random variables discussed previously, the fixed independent variables for the final EC model were region of study $(\mathrm{n}=3)$, causative mastitis pathogen $(\mathrm{n}=2)$, postmilking treatment $(\mathrm{n}=4)$, and the 2-way interactions of region and mastitis pathogen group and postmilking treatment's interaction with mastitis pathogen group. The fit statistics for the final EC model are presented in Table 4, and the model's parameter estimates and corresponding significance values are outlined in Supplemental Table 
S2 (http://dx.doi.org/10.3168/jds.2016-11359). The final EC model had a very low residual error $(0.88 \%)$, and the error assigned to individual studies was only $0.32 \%$ of the mean observed new IMI rate. Like the NE model before, the relatively small contribution of error from study suggests minimal between-study variability that was not accounted for by the terms included in the model and indicates that study heterogeneity was not a primary source of error in the final model.

Significant differences were detected among postmilking treatments for PNQI/mo $(P<0.0001$; Table $6)$. Undipped quarters $(0.0859 \mathrm{PNQI} / \mathrm{mo})$ had a higher new IMI rate $(P<0.01)$ than quarters dipped in iodine $(0.0127 \mathrm{PNQI} / \mathrm{mo})$, a chlorine compound (0.0258 PNQI/mo), or "other" active ingredients (0.0263 PNQI/ mo). Quarters dipped in iodine, chlorine compounds, or "other" did not differ in new IMI rate $(P>0.05)$. Based on these new IMI rates, it is clear that utilizing an EC study design effectively increases the new IMI rate for the challenge organism in undipped negative control quarters. By increasing the magnitude of difference between undipped negative control quarters and dipped quarters, fewer animals, a shorter trial duration, or both might be used. The lack of significance between the new IMI rates for quarters dipped in an iodine compound, chlorine compound, or "other" teat dips suggests that using an efficacious postmilking teat dip alone has a greater effect on reducing new Staph. aureus and Strep. agalactiae IMI rate than the specific active ingredients contained within a teat dip.

Overall, no difference in IMI rate was detected between Staph. aureus (0.0409 $\pm 0.0097 \mathrm{PNQI} / \mathrm{mo})$ and Strep. agalactiae (0.0344 $\pm 0.0096 \mathrm{PNQI} / \mathrm{mo} ; P>0.05)$; however, a significant interaction between causative mastitis pathogen and postmilking treatment was indicated by the final model $(P=0.0021)$. When the least squares means of this interaction were contrasted using Fisher's least significant difference test, only a single comparison yielded significant results that changed the interpretation of the model's main effects. In this instance, the new IMI rate for Staph. aureus (0.0997 $\pm 0.0098 \mathrm{PNQI} / \mathrm{mo})$ and Strep. agalactiae $(0.0710 \pm$ $0.0097 \mathrm{PNQI} / \mathrm{mo}$ ) differed for undipped negative control quarters $(P=0.0104)$. Conversely, when these new IMI rates were contrasted using the more conservative Tukey-Kramer's multiple comparisons procedure, significance was lost $(P=0.1641)$.

Percentage of new IMI/mo least squares means affected by region of study are reported and contrasted within causative mastitis pathogens in Table 7. Significant differences were detected among geographical regions and in the interactive term, region of study, and causative mastitis pathogen $(P<0.05)$. Overall means
Table 6. Postmilking treatment percentage of new quarter infections per month (PNQI/mo) ${ }^{1}$ least squares means across all mastitis pathogen groups and study locations for the experimental challenge data set

\begin{tabular}{lc}
\hline Postmilking treatment $^{2}$ & PNQI $/$ mo $( \pm$ SEM $)$ \\
\hline Undipped & $0.0859^{\mathrm{A}} \pm 0.0087$ \\
Iodine & $0.0127^{\mathrm{B}} \pm 0.0099$ \\
Chlorine compound & $0.0258^{\mathrm{B}} \pm 0.0095$ \\
Other & $0.0263^{\mathrm{B}} \pm 0.0106$ \\
\hline
\end{tabular}

$\overline{\mathrm{A}, \mathrm{B} P N Q I} / \mathrm{mo}$ not sharing the same superscript were significantly different $(P<0.05)$.

${ }^{1}$ Percentage of quarters eligible for infection that became infected during the trial divided by trial duration expressed as months.

${ }^{2}$ Cows' teats were either not treated with a postmilking teat dip (undipped) or dipped in teat dip containing iodine, a chlorine compound, or an "other" active ingredient.

demonstrated that studies conducted in the Southern region had a significantly greater IMI rate than those in the Pacific Northwest $(P<0.05)$, but not those in the Eastern region $(P>0.05)$. The new IMI rate for Staph. aureus was lower for studies conducted in the Pacific Northwest than the Eastern and Southern regions $(P<0.05)$. Even though all the studies included in the data set used the same strains of Staph. aureus and Strep. agalactiae as challenge organisms, the differences in new IMI rate by geographical region are not surprising. The differences in new IMI rate likely arise from disparities in herd management, established minor mastitis pathogen profiles that would influence the new Staph. aureus and Strep. agalactiae IMI rate (Nickerson and Boddie, 1994), and environmental factors (season, temperature, humidity, and so forth) among study locations that could not be included in the model. As a result, these factors would become associated with region of study especially because all the EC studies included in the data set were conducted in either Washington, Louisiana, or Vermont (Table 2), with multiple studies utilizing the same experimental herd. Even though new IMI rates possibly differing by geographical region is not surprising, it is important to recognize that the distribution of data across regions was lacking because only 1 study was included from the Eastern region and 2 from the Pacific Northwest. The lack of studies from these regions and the low new IMI rates reported in the Pacific Northwest studies were reflected in the high standard errors of the respective parameter estimates in Supplemental Table S2 (http://dx.doi.org/10.3168/ jds.2016-11359). In this instance, the model was able to detect significant effects for the Eastern and Southern regions with high precision; however, the lack of significance of the Pacific Northwest region parameter estimate suggests that regional differences observed in these data should be interpreted with reservation. The 
Table 7. Mastitis pathogen percentage of new quarter infections per month (PNQI/mo) ${ }^{1}$ least squares means within study location regions ${ }^{2}$ of the United States for the experimental challenge data set

\begin{tabular}{|c|c|c|c|c|c|c|}
\hline \multirow[b]{2}{*}{ Mastitis pathogen } & \multicolumn{6}{|c|}{ Region } \\
\hline & Eastern & SEM & Southern & SEM & Pacific Northwest & SEM \\
\hline Overall mean & $0.0527^{\mathrm{AB}}$ & 0.0206 & $0.0531^{\mathrm{A}}$ & 0.0040 & $0.0072^{\mathrm{B}}$ & 0.0141 \\
\hline
\end{tabular}

$\overline{\mathrm{A}, \mathrm{B}} \mathrm{PNQI} / \mathrm{mo}$ in a row not sharing the same superscript were significantly different $(P<0.05)$.

${ }^{1}$ Percentage of quarters eligible for infection that became infected during the trial divided by trial duration expressed as months.

${ }^{2}$ Study locations were classified as either the Southern (Louisiana), Eastern (Vermont), or the Pacific Northwest (Washington) region of the United States.

lack of a significant effect for the Pacific Northwest parameter estimate likely contributed to the negative least squares means identified in this analysis (Table 7).

Like the NE model before, the presence of a teat skin conditioning agent did not significantly influence the new Staph. aureus or Strep. agalactiae IMI rate $(P>$ $0.05)$. Poor teat skin condition has been demonstrated to increase Staph. aureus teat skin colonization (Fox et al., 1991), increasing the risk for new IMI (Pankey et al., 1984b). Despite this known risk factor, the simple addition of a skin conditioning agent to a teat dip may not independently influence IMI risk to a marked degree. Other factors such as ambient temperature, milking duration, and teat dip $\mathrm{pH}$ affect teat skin condition (Ohnstad et al., 2007) perhaps to greater degree. These other factors might mask the potential improvements in teat skin condition and subsequent IMI risk. When the results of the EC and NE models are taken together, they do not support the notion that a teat dip containing a skin conditioning agent would reduce new IMI incidence to a greater magnitude than a dip not containing a skin conditioner.

\section{CONCLUSIONS}

The results of the NE model confirm that teat dips containing only LDBSA are not effective in controlling the incidence of new Corynebacterium spp. IMI and that the concentration of a teat dip's active ingredient should not be used as an indicator of a teat dip's efficacy. Additionally, future natural exposure teat dip efficacy trials utilizing an undipped negative control treatment should employ a split udder experimental design instead of a split herd design to reduce the effect of a teat dip efficacy trial on herd udder health. The results from the EC model affirm that using an efficacious postmilking teat dip has a greater effect on controlling the new Staph. aureus and Strep. agalactiae IMI rate then the active ingredients contained within the teat dip itself. Also, from both the NE and EC models, no evidence was found that a teat dip containing a skin conditioner would have greater efficacy in preventing the new IMI rate than a dip not containing a teat skin conditioning agent.

\section{ACKNOWLEDGMENTS}

The authors thank W. Nelson Philpot, professor emeritus, Hill Farm Research Station, Louisiana State University Agriculture Center, Homer, for his insight and contributions to the discussion section of this manuscript.

\section{REFERENCES}

Boddie, R. L., and S. C. Nickerson. 1986. Efficacy of dodecylaminoalkyl glycine teat dip against Staphylococcus aureus and Streptococcus agalactiae mastitis. J. Dairy Sci. 69:258-259.

Boddie, R. L., and S. C. Nickerson. 1989. Efficacy of .18\% iodine teat dip against Staphylococcus aureus and Streptococcus agalactiae. J. Dairy Sci. 72:1063-1066

Boddie, R. L., and S. C. Nickerson. 1990. Efficacy of two iodophor postmilking teat germicides against Streptococcus agalactiae. J. Dairy Sci. 73:2790-2793.

Boddie, R. L., and S. C. Nickerson. 1992. Evaluation of postmilking teat germicides containing Lauricidin ${ }^{\infty}$, saturated fatty acids, and lactic acid. J. Dairy Sci. 75:1725-1730.

Boddie, R. L., and S. C. Nickerson. 1996. Efficacy of teat dips containing a hypochlorous acid germicide against experimental challenge with Staphylococcus aureus and Streptococcus agalactiae. J. Dairy Sci. 79:1683-1688.

Boddie, R. L., and S. C. Nickerson. 1997. Evaluation of two iodophor teat germicides: Activity against Staphylococcus aureus and Streptococcus agalactiae. J. Dairy Sci. 80:1846-1850.

Boddie, R. L., and S. C. Nickerson. 2002. Reduction of mastitis caused by experimental challenge with Staphylococcus aureus and Streptococcus agalactiae by use of a quaternary ammonium and halogenmixture teat dip. J. Dairy Sci. 85:258-262.

Boddie, R. L., S. C. Nickerson, and R. W. Adkinson. 1993. Evaluation of teat germicides of low iodine concentrations for prevention of bovine mastitis by Staphylococcus aureus and Streptococcus agalactiae. Prev. Vet. Med. 16:111-117.

Boddie, R. L., S. C. Nickerson, and R. W. Adkinson. 1997. Efficacies of teat germicides containing $0.5 \%$ chlorhexidine and $1 \%$ iodine during experimental challenge with Staphylococcus aureus and Streptococcus agalactiae. J. Dairy Sci. 80:2809-2814.

Boddie, R. L., S. C. Nickerson, and R. W. Adkinson. 1998. Germicidal activity of a chlorous acid-chlorine dioxide teat dip and a sodium 
chlorite teat dip during experimental challenge with Staphylococcus aureus and Streptococcus agalactiae. J. Dairy Sci. 81:2293-2298.

Boddie, R. L., S. C. Nickerson, and R. W. Adkinson. 2000. Efficacies of chlorine dioxide and iodophor teat dips during experimental challenge with Staphylococcus aureus and Streptococcus agalactiae. J. Dairy Sci. 83:2975-2979.

Boddie, R. L., S. C. Nickerson, and G. K. Kemp. 1994. Efficacy of two barrier teat dips containing chlorous acid germicides against experimental challenge with Staphylococcus aureus and Streptococcus agalactiae. J. Dairy Sci. 77:3192-3197.

Boddie, R. L., W. E. Owens, C. J. Foret, and P. Janowicz. 2004. Efficacy of a $0.1 \%$ iodine teat dip against Staphylococcus aureus and Streptococcus agalactiae during experimental challenge. J. Dairy Sci. 87:3089-3091

Boddie, R. L., J. L. Watts, and S. C. Nickerson. 1990. In vitro and in vivo evaluation of a $0.5 \%$ chlorhexidine gluconate teat dip. J. Am. Vet. Med. Assoc. 196:890-893.

Bray, D. R., R. P. Natzke, R. W. Everett, and C. J. Wilcox. 1983 Comparison of teat dips with differing iodine concentrations in prevention of mastitis infection. J. Dairy Sci. 66:2593-2596.

Devries, T. J., J. A. Deming, J. Rodenburg, G. Seguin, K. E. Leslie, and H. W. Barkema. 2011. Association of standing and lying behavior patterns and incidence of intramammary infection in dairy cows milked with an automatic milking system. J. Dairy Sci. 94:3845-3855.

Dodd, F. H., D. R. Westgarth, and T. K. Griffin. 1977. Strategy of mastitis control. J. Am. Vet. Med. Assoc. 170:1124-1128.

Drechsler, P. A., E. E. Wildman, and J. W. Pankey. 1990. Evaluation of a chlorous acid-chlorine dioxide teat dip under experimental and natural exposure conditions. J. Dairy Sci. 73:2121-2128.

Enger, B. D., L. K. Fox, J. M. Gay, and K. A. Johnson. 2015. Reduction of teat skin mastitis pathogen loads: Differences between strains, dips, and contact times. J. Dairy Sci. 98:1354-1361.

Foret, C. J., C. Corbellini, S. Young, and P. Janowicz. 2005. Efficacy of two iodine teat dips based on reduction of naturally occurring new intramammary infections. J. Dairy Sci. 88:426-432.

Foret, C. J., W. E. Owens, R. L. Boddie, and P. Janowicz. 2003. Efficacy of two iodine teat dips during experimental challenge with Staphylococcus aureus and Streptococcus agalactiae. J. Dairy Sci. 86:3783-3786.

Fox, L. K., C. Gradle, and A. Dee. 2006. Short communication: Disinfectant containing a complex of skin conditioners. J. Dairy Sci. $89: 2539-2541$.

Fox, L. K., J. A. Nagy, J. K. Hillers, J. D. Cronrath, and D. A. Ratkowsky. 1991. Effects of postmilking teat treatment on the colonization of Staphylococcus aureus on chapped teat skin. Am. J. Vet. Res. 52:799-802.

Goldberg, J. J., P. A. Murdough, A. B. Howard, P. A. Drechsler, J. W. Pankey, G. A. Ledbetter, D. A. Richards, and L. L. Day. 1994. Evaluation of a $1 \%$ iodophor postmilking teat sanitizer. J. Dairy Sci. 77:740-747.

Hogan, J. S., R. N. González, R. J. Harmon, S. C. Nickerson, S. P. Oliver, J. W. Pankey, and K. L. Smith. 1999. Laboratory Handbook on Bovine Mastitis. National Mastitis Council, New Prague, MN.

Hurvich, C. M., and C. L. Tsai. 1993. A corrected Akaike information criterion for vector autoregressive model selection. J. Time Ser. Anal. 14:271-279.

Kenward, M. G., and J. H. Roger. 1997. Small sample inference for fixed effects from restricted maximum likelihood. Biometrics 53:983-997.

National Mastitis Council. 2014. Summary of peer-reviewed publications on efficacy of premilking and postmilking teat disinfections published since 1980. Accessed April 20, 2015. http:// www.nmconline.org/docs/teatbibl.pdf.

Nickerson, S. C., and R. L. Boddie. 1994. Effect of naturally occurring coagulase-negative staphylococcal infections on experimental challenge with major mastitis pathogens. J. Dairy Sci. 77:2526-2536.

Nickerson, S. C., J. L. Watts, R. L. Boddie, and J. W. Pankey. 1986. Evaluation of .5\% and 1\% iodophor teat dips on commercial dairies. J. Dairy Sci. 69:1693-1698.
Ohnstad, I., G. A. Mein, J. R. Baines, M. D. Rasmussen, R. Farnsworth, B. R. Pocknee, T. C. Hemling, and J. E. Hillerton. 2007. Addressing teat condition problems. Pages 188-199 in Natl. Mastitis Counc. Annu. Mtg. Proc., San Antonio, TX. Natl. Mastitis Counc. Inc., New Prague, MN

Oliver, S. P., B. E. Gillespie, M. J. Lewis, T. L. Ingle, and H. H. Dowlen. 1994. Evaluation of chlorhexidine as a premilking teat disinfectant for the prevention of intramammary infections during lactation. J. Food Prot. 57:614-618.

Oliver, S. P., B. E. Gillespie, M. J. Lewis, S. J. Ivey, R. A. Almeida, D. A. Luther, D. L. Johnson, K. C. Lamar, H. D. Moorehead, and H. H. Dowlen. 2001. Efficacy of a new premilking teat disinfectant containing a phenolic combination for the prevention of mastitis. J. Dairy Sci. 84:1545-1549,

Oliver, S. P., S. H. King, M. J. Lewis, P. M. Torre, K. R. Matthews, and H. H. Dowlen. 1990. Efficacy of chlorhexidine as a postmilking teat disinfectant for the prevention of bovine mastitis during lactation. J. Dairy Sci. 73:2230-2235.

Oliver, S. P., S. H. King, P. M. Torre, E. P. Shull, H. H. Dowlen, M. J. Lewis, and L. M. Sordillo. 1989. Prevention of bovine mastitis by a postmilking teat disinfectant containing chlorous acid and chlorine dioxide in a soluble polymer gel. J. Dairy Sci. 72:3091-3097.

Oliver, S. P., M. J. Lewis, B. E. Gillespie, S. J. Ivey, L. H. Coleman, R. A. Almeida, W. Fang, and K. Lamar. 1999. Evaluation of a postmilking teat disinfectant containing a phenolic combination for the prevention of mastitis in lactating dairy cows. J. Food Prot. 62:1354-1357.

Oliver, S. P., M. J. Lewis, T. L. Ingle, B. E. Gillespie, and K. R. Matthews. 1993a. Prevention of bovine mastitis by a premilking teat disinfectant containing chlorous acid and chlorine dioxide. J. Dairy Sci. 76:287-292.

Oliver, S. P., M. J. Lewis, T. L. Ingle, B. E. Gillespie, K. R. Matthews, and H. H. Dowlen. 1993b. Premilking teat disinfection for the prevention of environmental pathogen intramammary infections. J. Food Prot. 56:852-855.

Oliver, S. P., M. J. Lewis, S. H. King, B. E. Gillespie, T. Ingle, K. R. Matthews, H. H. Dowlen, P. A. Drechsler, E. E. Wildman, and J. W. Pankey. 1991. Efficacy of a low concentration iodine postmilking teat disinfectant against contagious and environmental mastitis pathogens in two dairy herds. J. Food Prot. 54:737-742.

Oura, L. Y., L. K. Fox, C. C. Warf, and G. K. Kemp. 2002. Efficacy of two acidified chlorite postmilking teat disinfectants with sodium dodecylbenzene sulfonic acid on prevention of contagious mastitis using an experimental challenge protocol. J. Dairy Sci. 85:252-257.

Pankey, J. W., R. L. Boddie, and S. C. Nickerson. 1985a. Efficacy evaluation of two new teat dip formulations under experimental challenge. J. Dairy Sci. 68:462-465.

Pankey, J. W., R. L. Boddie, and W. N. Philpot. 1984a. Evaluation of linear dodecyl benzene sulfonic acid as a teat dip in a commercial dairy. J. Dairy Sci. 67:1354-1358.

Pankey, J. W., and P. A. Drechsler. 1993. Evolution of udder hygiene. Premilking teat sanitation. Vet. Clin. North Am. Food Anim. Pract. 9:519-530.

Pankey, J. W., R. J. Eberhart, A. L. Cuming, R. D. Daggett, R. J. Farnsworth, and C. K. McDuff. 1984b. Uptake on postmilking teat antisepsis. J. Dairy Sci. 67:1336-1353.

Pankey, J. W., S. C. Nickerson, and R. L. Boddie. 1984c. Evaluation of linear dodecyl benzene sulfonic acid teat dip under experimental challenge. J. Dairy Sci. 67:1327-1330.

Pankey, J. W., W. N. Philpot, and R. L. Boddie. 1983. Efficacy of low concentration iodophor teat dips against Staphylococcus aureus. J. Dairy Sci. 66:155-160.

Pankey, J. W., J. L. Watts, and S. C. Nickerson. 1985b. Field studies on linear dodecyl benzene sulfonic acid teat dip. J. Dairy Sci 68:1523-1530.

Pankey, J. W., E. E. Wildman, P. A. Drechsler, and J. S. Hogan. 1987. Field trial evaluation of premilking teat disinfection. J. Dairy Sci. 70:867-872.

Peters, R. R., S. Komaragiri, M. J. Paape, and L. W. Douglass. 2000. Evaluation of $1.6 \%$ phenol as a premilking and postmilking teat 
dip in preventing new bovine intramammary infections. J. Dairy Sci. 83:1750-1757.

Pitkälä, A., M. Haveri, S. Pyörälä, V. Myllys, and T. Honkanen-Buzalski. 2004. Bovine mastitis in Finland 2001-Prevalence, distribution of bacteria, and antimicrobial resistance. J. Dairy Sci. 87:2433-2441.

Quirk, T., L. K. Fox, D. D. Hancock, J. Capper, J. Wenz, and J. Park. 2012. Intramammary infections and teat canal colonization with coagulase-negative staphylococci after postmilking teat disinfection: Species-specific responses. J. Dairy Sci. 95:1906-1912.

Sauvant, D., P. Schmidely, J. J. Daudin, and N. R. St-Pierre. 2008. Meta-analyses of experimental data in animal nutrition. Animal $2: 1203-1214$.

Saxton, A. M. 1998. A macro for converting mean separation output to letter groupings in Proc Mixed. Pages 1243-1246 in Proc. 23rd SAS Users Group Int. SAS Institute Inc., Cary, NC.
Schmidt, A. L., S. P. Oliver, and M. E. Fydenkevez. 1984. Evaluation of experimental teat dip containing sodium chlorite and lactic acid by excised teat assay. J. Dairy Sci. 67:3075-3080.

St-Pierre, N. R. 2001. Invited review: Integrating quantitative findings from multiple studies using mixed model methodology. J. Dairy Sci. 84:741-755.

Watts, J. L., S. C. Nickerson, R. L. Boddie, and C. H. Ray. 1991 Effects of a $1.94 \%$ sulfonic acid teat dip and a $1 \%$ iodophor teat dip on teat canal infections in lactating dairy cows. J. Dairy Sci. 74:1115-1123.

Wilson, D. J., R. N. Gonzalez, and H. H. Das. 1997. Bovine mastitis pathogens in New York and Pennsylvania: Prevalence and effects on somatic cell count and milk production. J. Dairy Sci. 80:2592-2598 